\title{
Pengaruh Konseling Terhadap Kepatuhan Pengobatan Obat Anti Tuberkulosis di Poli Paru Rumah Sakit Penyakit Infeksi (RSPI) Prof. Dr. Sulianti Saroso Tahun 2016
}

\author{
Effect of Counseling on Treatment Adherence OAT in Poly Pulmonary Medicine \\ In Infectious Disease Hospital Prof. Dr. Sulianti Saroso 2016
}

\author{
Dian Noviati Kurniasih \\ Rumah Sakit Penyakit Infeksi (RSPI) Prof. Dr. Sulianti Saroso
}

Korespondensi Penulis :

Dian Novita Kurniasih

Email : dianali79@ymail.com

\begin{abstract}
Abstrak
Latar belakang : Tuberkulosis merupakan penyakit kronik yang keberhasilan pengobatannya adalah kepatuhan dari penderita. Masalah yang sering muncul pada pengobatan TB adalah ketidakpatuhan pengobatan dan dapat meningkatkan kejadian putus obat, kekambuhan, kematian, dan peningkatan penularan. Penelitian ini bertujuan mengetahui pengaruh konseling metode cognitive Behaviour Therapy (CBT) terhadap kepatuhan pengobatan Obat Anti Tuberkulosis (OAT.

Metode : Desain dalam penelitian ini adalah quasi eksperimen dengan rancangan control group. Populasinya adalah semua pasien yang sudah mendapat OAT tahap awal. Sampel dalam penelitian ini adalah 68 sampel. Penelitian ini menggunakan kuesioner dan lembar observasi.

Hasil : Kepatuhan Pengobatan OAT pada penderita TB Paru sebesar 57,35\%. Faktor yang tidak berhubungan dengan kepatuhan pengobatan OAT antara lain: umur (Pvalue $=0,390)$, jenis kelamin (Pvalue $=0,327$ ), pendidikan (Pvalue $=0,120)$, dan pekerjaan (Pvalue $=0,809)$. Ada hubungan yang bermakna adalah pengetahuan $(P$ value $=0,000)$ dan konseling $(P v a l u e=0,00)$ dengan kepatuhan. Faktor dominan yang berhubungan dengan kepatuhan adalah konseling dengan nilai Odds Ratio 36,470..

Kesimpulan : Faktor yang paling dominan berpengaruh terhadap kepatuhan pengobatan OAT adalah faktor konseling.
\end{abstract}

Kata Kunci : Kepatuhan, Konseling, Obat Anti Tuberkulosis (OAT)

\begin{abstract}
Background : Tuberculosis is a chronic disease and the success of treatment is depend on the compliance of the patient. The problem that often arises in TB treatment is poor adherence treatment and may increase the incidence of drug withdrawal, relapse, death, and increased transmission. The purpose of this study was to determine the effect of cognitive Behaviour Therapy (CBT) counseling on treatment adherence OAT.

Methods : Design of this research is quasi-experimental design with control group. The population is all patients who have got OAT early stage. The sample in this study was 68 samples. This study used a questionnaire and observation

Results : Treatment Compliance OAT in patients with pulmonary tuberculosis amounted to $57.35 \%$. Factors not associated with OAT medication adherence include: age (pvalue $=0.390)$, gender ( $p v a l u e=$ 0.327 ), education (pvalue $=0.120$ ), and employment (pvalue $=0.809$ ). There was a significant relationship is knowledge (pvalue $=0.000$ ) and counseling (pvalue $=0.00)$ with compliance. The dominant factor associated with compliance is counseling with a value of 36.470 Odds Ratio ..

Conclusion : The most dominant factor influence on treatment adherence counseling OAT is a factor.
\end{abstract}

Keywords : adherence, Counseling, Anti-Tuberculosis Drugs 


\section{Pendahuluan}

Tuberkulosis (TB) paru merupakan salah satu masalah kesehatan masyarakat di Indonesia yang memerlukan perhatian. Indonesia salah satu dari 4 negara terbesar di dunia sebagai penyumbang penderita TB terbanyak setelah negara China, India, dan Afrika Selatan. Keberhasilan pengobatan di Indonesia mengalami penurunan pada tahun 2014 sebesar $81,3 \%$ dan yang tidak sesuai dengan standar WHO sebesar 85\%. Angka Nasional proporsi kasus relaps dan gagal pengobatan di bawah $2 \%$ dimana salah satu penyebabnya karena ketidakpatuhan dapat mengakibatkan drop out pada pengobatan TB. ${ }^{1,2}$

Rumah Sakit Prof DR Sulianti Saroso, merupakan salah satu rumah sakit rujukan penyakit infeksi. Penyakit TB merupakan penyakit nomor 2 dari 10 penyakit terbanyak di rawat jalan. Data pasien berobat ke poli paru periode bulan Oktober sampai Desember 2015 terdapat sekitar $17,1 \%$ jumlah pasien bermasalah dalam pengobatan OAT dan dapat berpengaruh terhadap keberhasilan program pengobatan TB. Masalah pengobatan OAT diantaranya kambuh (4,1\%), Gagal (2\%) dan kasus putus obat serta drop out dikarenakan ketidakpatuhan. $^{3}$

Permasalahan utama dalam pengobatan TB adalah pengobatan tidak selesai sebelum masa pengobatan karena ketidakpatuhan dalam pengobatan. Dampak ketidakpatuhan mengakibatkan tingginya tingkat penularan dan tingginya kasus resistensi kuman terhadap OAT yang membutuhkan biaya yang lebih besar dan bertambah lamanya pengobatan (Kemenkes Republik Indonesia, 2014). ${ }^{2}$ Menurut penelitian Komalasari di karawang menyatakan bahwa ada Pengaruh Konseling Metode Perilaku Terhadap Kepatuhan Pengobatan Klien Tb Paru fase Intensif (Pvalue $=0,0001) .{ }^{4}$ Penelitian ini berbeda dengan yang dilakukan oleh peneliti dimana peneliti menggunakan konseling dengan metode CBT (Cognitif Behaviour Therapy) yang mengkombinasikan antara terapi kognitif dan perilaku yaitu mengelola pikiran dan cara berpikir menjadi lebih positif sehingga mengubah cara berperilaku dan tindakan. Tujuan dari penelitian ini adalah untuk diketahui pengaruh konseling terhadap kepatuhan pengobatan OAT di Poli Paru RSPI Prof Dr Sulianti Saroso Jakarta Utara.

\section{Metode}

Menggunakan desain quasi eksperimen dengan rancangan control group. Kelompok intervensi diberikan perlakuan intervensi konseling dengan metode CBT (Cognitif Behaviour Therapy) selama 30 menit sebanyak 3 
kali dalam 28 hari yaitu hari kesatu (kunjungan ke-1), hari keempat belas (kunjungan ke-2), hari keduapuluh delapan (kunjungan ke-3) dan kelompok kontrol hanya diberikan informasi sesuai kebiasaan Rumah sakit selama 28 hari. Postest dilakukan pada hari ke 28 setelah pemberian konseling. Waktu pelaksanaan penelitian ini dilakukan mulai pada bulan Juni sampai Juli 2016 di Poli DOTS RSPI-SS. Jumlah sampel sebanyak 68 responden. Analisa bivariat menggunakan uji chi square dan multivariat menggunakan uji regresi logistik ganda.
Hasil

Analisis dilakukan terhadap karakteristik pasien, pengetahuan dan pemberian konseling terhadap kepatuhan pengobatan OAT. Variabel yang tidak berhubungan dengan kepatuhan pengobatan OAT adalah Umur, jenis kelamin, pendidikan, dan pekerjaan (Pvalue>0,05). Variabel pengetahuan dan konseling berhubungan dengan kepatuhan pengobatan (Pvalue $<0,05)$. Selanjutnya variabel yang masuk permodelan yaitu variabel yang mempunyai nilai $p<0,25$ yaitu pendidikan, pengetahuan dan konseling. Hasil dapat dilihat pada tabel 1.

Tabel 1. Analisis Hubungan antara Karakteristik Pasien, Pengetahuan dan Konseling Terhadap Kepatuhan Pengobatan OAT Di Poli Paru RSPI Dr Prof Sulianti Saroso Jakarta Tahun 2016

\begin{tabular}{|c|c|c|c|c|c|c|c|c|}
\hline \multicolumn{2}{|c|}{ Variabel Penelitian } & \multicolumn{4}{|c|}{ Kepatuhan } & \multirow{3}{*}{$\begin{array}{l}\text { OR } \\
\text { kasar }\end{array}$} & \multirow{3}{*}{$\begin{array}{l}\text { 95\% interval } \\
\text { kepercayaan }\end{array}$} & \multirow{3}{*}{$\begin{array}{c}\mathrm{P} \\
\text { value }\end{array}$} \\
\hline & & \multicolumn{2}{|c|}{$\begin{array}{l}\text { Patuh } \\
(n=39)\end{array}$} & \multicolumn{2}{|c|}{$\begin{array}{l}\text { Tidak } \\
\text { Patuh } \\
(\mathrm{n}=29) \\
\end{array}$} & & & \\
\hline & & $\mathrm{n}$ & $\%$ & $\mathrm{n}$ & $\%$ & & & \\
\hline \multirow[t]{2}{*}{ Umur } & 15- 55 tahun & 37 & 94,9 & 25 & 82,2 & \multirow{2}{*}{0,338} & \multirow{2}{*}{$0,057-1,987$} & \multirow{2}{*}{0,390} \\
\hline & $56-65$ tahun & 2 & 5,1 & 4 & 13,8 & & & \\
\hline \multirow[t]{2}{*}{ Jenis kelamin } & Laki & 17 & 58,6 & 17 & 43,6 & \multirow{2}{*}{1,833} & \multirow{2}{*}{$0,693-4,851$} & \multirow{2}{*}{0,327} \\
\hline & Perempuan & 22 & 56,4 & 12 & 41,4 & & & \\
\hline \multirow[t]{2}{*}{ Pendidikan } & Rendah & 9 & 23,1 & 12 & 41,4 & \multirow{2}{*}{2,353} & \multirow{2}{*}{ 0,824-6,719 } & \multirow{2}{*}{0,120} \\
\hline & Tinggi & 30 & 76,9 & 17 & 58,6 & & & \\
\hline \multirow[t]{2}{*}{ Pekerjaan } & Tidak Bekerja & 19 & 48,7 & 13 & 44,8 & \multirow{2}{*}{0,855} & \multirow{2}{*}{$0,326-2,243$} & \multirow{2}{*}{0,809} \\
\hline & Bekerja & 20 & 51,3 & 16 & 55,2 & & & \\
\hline \multirow[t]{2}{*}{ Pengetahuan } & Kurang & 6 & 23,1 & 20 & 76,9 & \multirow{2}{*}{0,082} & \multirow{2}{*}{$0,025-0,264$} & \multirow{2}{*}{0,000} \\
\hline & Baik & 33 & 78,6 & 9 & 21,4 & & & \\
\hline \multirow[t]{2}{*}{ Konseling } & Ya & 31 & 79,5 & 3 & 10,3 & \multirow{2}{*}{33,583} & \multirow{2}{*}{$8,072-139,719$} & \multirow{2}{*}{0,000} \\
\hline & Tidak & 8 & 20,5 & 26 & 89,7 & & & \\
\hline
\end{tabular}


Tabel 2. Hasil Akhir Analisis Regresi Linier Ganda Variabel yang Berpengaruh Terhadap Kepatuhan Pengobatan OAT Di Poli Paru RSPI Dr Prof Sulianti Saroso Jakarta Tahun 2016

\begin{tabular}{|c|c|c|c|c|c|c|c|c|}
\hline \multicolumn{2}{|c|}{ Variabel Penelitian } & \multicolumn{4}{|c|}{ Kepatuhan } & \multirow{3}{*}{$\begin{array}{c}\text { OR } \\
\text { suaian } \\
*\end{array}$} & \multirow{3}{*}{$\begin{array}{c}95 \% \text { interval } \\
\text { kepercayaan }\end{array}$} & \multirow{3}{*}{$\begin{array}{c}\mathrm{P} \\
\text { value }\end{array}$} \\
\hline & & \multicolumn{2}{|c|}{ Patuh $(n=39)$} & \multicolumn{2}{|c|}{$\begin{array}{l}\text { Tidak Patuh } \\
(\mathrm{n}=29)\end{array}$} & & & \\
\hline & & $n$ & $\%$ & $n$ & $\%$ & & & \\
\hline \multirow[t]{2}{*}{ Pendidikan } & Rendah & 9 & 23,1 & 12 & 41,4 & \multirow{2}{*}{3,012} & \multirow{2}{*}{$0,661-13,718$} & \multirow{2}{*}{0,154} \\
\hline & Tinggi & 30 & 76,9 & 17 & 58,6 & & & \\
\hline \multirow[t]{2}{*}{ Konseling } & $\mathrm{Ya}$ & 31 & 79,5 & 3 & 10,3 & \multirow{2}{*}{36,470} & \multirow{2}{*}{$8,193-162,329$} & \multirow{2}{*}{0,000} \\
\hline & Tidak & 8 & 20,5 & 26 & 89,7 & & & \\
\hline
\end{tabular}

Analisis lanjut terhadap variabel pendidikan, pengetahuan dan konseling. Hasil analisis multivariate diperoleh variabel yang berhubungan bermakna dengan kepatuhan pengobatan OAT adalah konseling, sedangkan variabel pendidikan adalah variabel counfounding. Variabel yang paling berpengaruh/ dominan terhadap kepatuhan pengobatan OAT adalah konseling dengan hasil analisis didapatkan OR (Odds Ratio) adalah 36,470 artinya penderita TB Paru yang mendapatkan konseling CBT (Cognitif Behaviour Therapy) akan memberikan peluang 36 kali lebih besar patuh dalam melakukan pengobatan OAT dibanding penderitan TB Paru yang tidak mendapatkan konseling setelah dikontrol oleh variabel pendidikan. Hasil dapat dilihat pada tabel 2 .

\section{Pembahasan}

Hasil analisis menunjukkan bahwa variabel dengan nilai $p<0,05$ yang artinya berhubungan adalah pengetahuan dan konseling.

Pengetahuan penderita TB berhubungan dengan kepatuhan pengobatan OAT dengan nilai Pvalue= 0,000 . Hasil ini sejalan dengan Hasil penelitian Susilowati, dkk menyatakan ada hubungan yang bermakna antara pengetahuan pasien TBC dengan kepatuhan minum obat anti tuberkulosis (OAT). Hasil penelitian ini juga didukung oleh teori Notoatmodjo yang mengemukakan bahwa tindakan seseorang terhadap masalah kesehatan pada dasarnya dipengaruhi oleh pengetahuanseseorang tentang masalah tersebut. Dalam hal ini, pengetahuan yang dimiliki oleh penderita TB Paru berhubungan dengan tingkat kepatuhan berobat, semakin tinggi pengetahuan penderita TB Paru tentang penyakitnya maka akan semakin patuh berobat. ${ }^{5,6}$

$$
\text { Hasil analisis lanjutan }
$$

menunjukkan bahwa ada pengaruh konseling terhadap kepatuhan pengobatan OAT di Poli Paru RSPI. 
Prof. Dr. Sulianti Saroso dengan Pvalue $=0,000$. Hal ini sejalan dengan penelitian Loriana dkk di Samarinda bahwa ada pengaruh efek konseling terhadap kepatuhan berobat penderita TB paru. Hasil penelitian ini diperoleh Penderita TB Paru 57,35\% adalah patuh setelah diberikan konseling. ${ }^{7}$

Pemberian konseling dapat memberikan stimulus pada klien untuk berfikir dimana seseorang yang mempunyai pola pikir negatif akan berubah berpola fikir positif sehingga klien mampu melakukan perubahan perilaku kearah yang positif atau adaptif. ${ }^{8}$ Metode konseling ini lebih baik daripada pemberian informasi yang biasa dilakukan di RSPI-SS sehingga mampu meningkatkan kepatuhan pengobatan karena metode CBT mengubah emosi dan perilaku klien TB terhadap pengobatan OAT dengan cara mengubah pikiran negatif seperti lupa, kecerobohan, menghentikkan obat ketika merasa lebih baik dan merasa lebih buruk (efek samping obat) menjadi berfikir lebih positif dengan melakukan penatalaksanaan perawatan yang dianjurkan dan sesuai dengan nasehat medis atau kesehatan tentang cara minum obat, pemantauan mandiri terhadap gejala penyakit (efek samping obat yang timbul), evaluasi kesehatan kontrol kembali sesuai jadwal, kesesuain jumlah obat dan peran $\mathrm{PMO}^{2,9,10}$

Hasil analisis multivariat didapakan bahwa faktor dominan yaitu Konseling yang berpengaruh terhadap pengobatan OAT (Pvalue $=0.000$ ), dilihat dari hasil analisis didapatkan OR (Odds Ratio) adalah 36,470 artinya penderita TB Paru yang mendapatkan konseling $C B T$ (Cognitif Behaviour Therapy) akan memberikan peluang 36 kali lebih besar patuh dalam melakukan pengobatan OAT dibanding penderitan TB Paru yang tidak mendapatkan konseling. Hasil penelitian ini Sejalan dengan penelitian komalasari yang menyatakan ada pengaruh konseling terhadap kepatuhan pengobatan klien TB paru fase intensif. ${ }^{4}$ Astin menyatakan pasien yang menjalani pengobatan TB paru membutuhkan informasi ataupun konseling kesehatan tentang perawatan dan pengobatan TB. ${ }^{11}$ Pemberian konseling mampu menyelesaikan masalah dengan memberikan informasi sehingga seseorang mampu menyesuaikan diri dan mampu pengambilan keputusan terhadap masalah yang dihadapinya. Didukung teori cognitive Behaviour Therapy (CBT) dengan mengkombinasikan antara terapi kognitif dan perilaku yaitu mengelola pikiran dan cara berpikir menjadi lebih positif sehingga 
mengubah cara berperilaku dan tindakan. ${ }^{12,13}$

\section{Kesimpulan}

Pengetahuan dan konseling berhubungan dengan kepatuhan pengobatan OAT dimana konseling merupakan faktor dominan yang mempengaruhi kepatuhan pengobatan OAT.

\section{Ucapan Terima Kasih}

Penulis mengucapkan terima kasih kepada institusi RSPI Prof Dr. Sulianti Saroso dan semua pihak yang terlibat dan berkonstribusi dalam penelitian ini

\section{Daftar Pustaka}

1. Kemenkes RI. Profil kesehatan Indonesia 2013. Jakarta; 2014.

2. Kemenkes RI. Modul Pelatihan Test dan Konseling HIV/AIDS. In Jakarta; 2015.

3. Rumah Sakit Penyakit Infeksi Prof Dr Sulianti Saroso. Register Rumah Sakit Penyakit Infeksi Prof Dr Sulianti Saroso. Jakarta;

4. Komalasari O. Pengaruh Konseling Metode Perilaku terhadap Kepatuhan Pengobatan Klien TB Paru Fase Inetensif di wilayah Kerja Dinas Kesehatan Kabupaten Kerawang. Universitas Padjajaran; 2013.

5. Susilowati, Ridwan A, Cahyono S. Hubungan Pengetahuan Pasien Tbc Tentang Penyakit Tbc Dengan Kepatuhan Minum Obat Anti Tuberkulosis ( Oat ). J AKP.
2012;(6):49-55.

6. Notoatmodjo S. Promosi kesehatan, teori dan Aplikasi. Jakarta: Rineka Cipta; 2010.

7. Loriana R. Efek konseling terhadap pengetahuan, sikap dan kepatuhan berobat penderita tuberkulosis paru. J Husada Mahakam. 2013;III(6):281-7.

8. Amaliah R. Faktor-faktor yang Berhubungan dengan Kegagalan Konversi Penderita TB Paru BTA Positif Pengobatan Fase Intensif di Kabupaten Bekasi Tahun 2010. Universitas Indonesia; 2012.

9. Kurniawan, Nurmasadi, Siti Rahmalia . Faktor-Faktor Yang Mempengaruhi Keberhasilan Pengobatan Tuberkulosis Paru. Jom. 2015;2(1).

10. Hutapea TP. Pengaruh Dukungan Keluarga terhadap Kepatuhan Minum Obat Anti Tuberkulosis. Pengaruh Dukungan Kel terhadap Kepatuhan Minum Obat Anti Tuberkulosis. 2005;(Tuberkulosis):1-11.

11. Astin F. Marley C. PrimaryTuberculosis And Health Infor-mation Provisi. 2010.

12. Haniyah S, Wibowo TH. Kaitan Tingkat Pendidikan Dengan Kepatuhan Minum Obat Pada Pasien Tuberkulosis (TB) Paru. J shb. 2006;1-6.

13. Dhewie GI, Armiyati $Y$, Supriyono M. Hubungan Antara Pengetahuan, Sikap Pasien Dan Dukungan Keluarga Dengan Kepatuhan Minum Obat Pada Pasien Tb Paru Di BKPM Pati. 2011; 